\title{
Enterprise Internal Control and Accounting Information Quality
}

\author{
Mengmeng Luo \\ Management School, Ji'nan University, Guangzhou, China \\ Email: 1275661038@qq.com
}

How to cite this paper: Luo, M. M. (2017). Enterprise Internal Control and Accounting Information Quality. Journal of Financial Risk Management, 6, 16-26. https://doi.org/10.4236/jfrm.2017.61002

Received: January 19, 2017

Accepted: February 26, 2017

Published: March 1, 2017

Copyright $\odot 2017$ by author and Scientific Research Publishing Inc. This work is licensed under the Creative Commons Attribution International License (CC BY 4.0).

http://creativecommons.org/licenses/by/4.0/

\begin{abstract}
Since the Enron, WorldCom financial fraud, issued after the Sarbanes-Oxley corporate internal control problem has received the widespread attention worldwide. In China, in June 2008, the ministry of finance, securities and futures commission, the national audit office, the China banking regulatory commission, insurance regulatory commission and other five ministries jointly issued the described as China's version of Sarbanes-Oxley "enterprise internal control basic norms", but the enterprise internal control system is not yet mature, mainly embodied in the internal audit, internal governance structure and the implementation of the internal control system, etc., thus causes problems in the quality of accounting (the accounting information fraud, etc.). So this article analyzes China accounting information and the current situation of internal control and the effect of internal control on the quality of accounting information, and puts forward constructive suggestions and comments.
\end{abstract}

\section{Keywords}

Internal Control, Accounting Information, Suggestions and Comments

\section{Introduction}

Corporate scandals and auditing failures, such as those of Enron, WorldCom and Tyco, have motivated regulators to address the effectiveness of internal controls (Chen et al. 2015). Enterprise internal control is effective control method of supervision and management and risk prevention. Internal control defined in the COSO explicitly pointed out that the goal of corporate internal control is to make sure the reliability of financial reporting, operating efficiency and effectiveness, compliance with the relevant laws and regulations. China's new accounting standards and regulations provide that: the accounting information quality requires the accounting information provided by enterprise financial re- 
port to be true and reliable. Both above focus on the quality of accounting information. Therefore, the enterprise internal control and accounting information quality are very important for enterprises. Besides, the relationship of the two is very close.

The most basic feature of the accounting information is decision usefulness. In addition, the authenticity and reliability of accounting information is the basic premise and condition of ensuring accounting information users to make the right decisions. Successful companies expand due to the effective internal control. On the contrary, the failure of internal control will make the enterprises suffer huge losses, even bankruptcy. Investigation conclusion made by Loyalty and Guarantee Companies in the United States is that $70 \%$ of the company's bankruptcy is due to lack of effective internal control. Barings bank, "Zheng Baiwen", Abandonment, Cao once glorious enterprises, collapsed in immediately liking a building. What is only one reason is that the internal control system that is known as the "stabilizer" of modern enterprise steady development in these enterprises becomes a dead letter. However, to some extent, these events also exposed that the internal control can play a key role in the accounting information quality. In addition, one of the goals of the internal control is to ensure authenticity and integrity of the accounting information. Therefore, the quality of internal control can play a vital role in improving the quality of accounting information, ensuring the safety of the assets of companies, reducing the financial fraud and improving the ability of the risk prevention.

After Sarbanes-Oxley Act, the enterprise internal control problem has received the widespread attention around the world. In June 2008, the ministry of finance, securities and futures commission, the national audit office, the China banking regulatory commission, insurance regulatory commission jointly issued the described as China's version of Sarbanes-Oxley "enterprise internal control basic norms". In April 2010, the ministry of finance, securities and futures commission, the national audit office, the China banking regulatory commission, insurance regulatory commission jointly released "the form a complete set of the internal control guidelines". Both of above mark that the Chinese enterprise internal control standard system has been formed (Altamuro and Beatty, 2010). Thus, at least from the relevant regulatory authorities or from the point of view of the functional departments of enterprise, internal control has become a very important economic elements influencing accounting, auditing, banking, insurance, securities. Under this background, more and more scholars research internal control.

At present scholars all agree: to improve the quality of accounting information, we must strengthen and improve the internal control. To a large extent, effectiveness and integrity of internal control determine the quality of accounting information. To improve accounting information quality problems must perfect the internal control system. Therefore, this article mainly analyzes the current situation of the accounting information and internal control in China, and then analyzes the role of internal control in accounting information quality, at last, 
puts forward some suggestions.

In this paper, the structure of the arrangement is as follows: The first part introduces the current situation of the quality of accounting information and internal control in China. The second part introduces the role of the internal control in accounting information quality. The last part is suggestions about how to improve accounting information quality from the perspective of internal control.

\section{The Present Situation and Cause Analysis of Accounting Information Quality in China}

\subsection{The Current Situation of the Quality of Accounting Information}

\subsubsection{From the Perspective of Accounting Information Processing}

The authenticity of accounting information specifically reflects the essential connotation of the financial information. In addition, the authenticity of accounting information is the main content of the accounting information quality. Accounting information quality has timeliness. Therefore, on the basis of ensuring timely disclosure of accounting information, enterprises must ensure its authenticity. However, at present, there is the crux of the low quality of accounting information in most companies of China. Information distortion phenomenon is widespread in China. Information distortion phenomenon in accounting information processing mainly displays in the following aspects. First of all, some listed companies cannot check the relevant accounting data and information timely, effectively and detail when they prepare financial and accounting reports. Therefore, phenomenon above can cause enterprise decisionmaking errors. Secondly, some enterprises cannot carry out some clear rules of the accounting standards effectively, cannot consider the company's economic environment from all angles, and cannot take effective methods to improve the phenomenon of low enterprise accounting information quality. Finally, some enterprises only look at problems from the perspective of their own. They use different methods of share-based payment to operation interests, cannot adjust the fair value, and cannot master number of exercise. Phenomenon all above can expose problems and disadvantages of accounting adequately, to a large extent, determines the quality of the accounting information authenticity, validity and reliability, bury a potential and long hidden danger for users of the accounting information to make decisions correctly and scientifically, and make each work be heavily influenced by the negative effect.

\subsubsection{From the Perspective of Accounting Information Disclosure}

Imperfect information disclosure phenomenon is widespread in the enterprise annual financial statements. The accounting information disclosure involving the breadth and width is not the best, causing that the accounting information that should be disclosed cannot be disclosed and the accounting information that enterprises do not require is disclosed in detail (Skaife et al. 2013). All of these above can cause the higher cost of information disclosure and cause disclosure of information chaos and uncertain phenomenon. For example, in the 
investment real estate enterprises, accounting information users cannot see whether the real estate companies that need convert type have transition conditions. Besides, in some listed companies, the types of the estimated liabilities are not in accordance with the common contingency criteria to set out, but according to their own simplistic thinking simple to list. In terms of inventory, many enterprises did not explicitly disclosure the specific inventory devaluation, reversal of the provision for inventory devaluation and resale of inventory. In the debt restructuring, there has been inconsistency before and after the phenomenon of debt restructuring gains and losses. In terms of disclosure of financial instruments, classification basis of financial instruments held by the enterprises is not enough to disclose, which brings unexpected hardships to accounting information users. Finally, many companies do not have the quality of the ability to respond to changes flexibly, just copy norms and codes, and cannot fully reflect the company's own investment structure.

\subsection{The Reasons for Incomplete Accounting Information}

From China's current situation, both listed companies and non-listed companies, accounting information is difficult to achieve the quality standards highquality accounting information should have. And this situation of poor quality of accounting information in China is not accidental. There is a deep level reason. The causes of these conditions are both objective and subjective.

\subsubsection{Objective Reasons for the Low Quality of Accounting Information in China}

First of all, the accounting system, accounting standards, the limitations of accounting technology itself is an objective factor that lead to accounting information be not sufficient and not true reflect business performance. In China, although laws and regulations such as the Accounting Law, the Company Law and the Basic Accounting Standards have been formulated or revised in recent years, these laws and regulations are formulated according to the specific circumstances of the political and economic environment in a certain period of time, Often with a certain lag and limitations, which makes the accounting staff in dealing with new economic business, often with greater flexibility, leading to the possibility of accounting information distortion. In addition, some of these laws and regulations there are some vague content, do not develop the appropriate implementation details and result in the practical work of poor operability.

Second, the use of computer accounting brings some problems. The introduction of computers into the accounting work is an improvement, but because the computer literacy of accounting personnel generally is not high, although proficient in accounting business, but limited knowledge of computer knowledge, computer knowledge and accounting knowledge cannot be combined. So it is easy to cause accounting information personnel in accounting information processing loopholes. Coupled with the existing financial software security defects in general, the actual use of the process is also a lack of commonality and standards, making the use of computer units in the internal control there are of- 
ten many loopholes. Some of the accounting for their own interests is likely to take advantage of this false accounting information in the false, thus affecting the importance of accounting information and authenticity and the problem because of its "invisible", the harm may be greater.

Finally, the social audit supervision is also ineffective lead to another reason for the low quality of accounting information. The CPA's duty is to provide an assurance service to the financial statements of the enterprise in an objective and impartial manner so as to ensure the authenticity of the accounting information. However, due to the uneven level of certified public accountants, coupled with many people lack of professional ethics and poor management and other reasons, and cannot really play its due role (Zhang, 2014).

\subsubsection{Subjective Reasons for the Low Quality of Accounting Information in China}

From the point of view of the information provider, the information provider has a motive for providing false accounting information for various purposes.

The interests of enterprises in the accounting information related to the interests are in the primary position. By providing false accounting information, an enterprise can defraud the trust of investors, creditors and the relevant authorities of the state, and thus obtain economic benefits such as investment, loan or reduction of tax expenses.

The chief executives rely on the right to influence or force the accountants to gain the trust of the investors by making false accounting information, and thus gain the interests of positions, salaries, stock appreciation, etc. Accounting personnel, as the direct producers of accounting information, also play an important role in the quality of accounting information. Some accountants cannot keep their professional ethics, cannot adhere to the principle of improper performance of their duties, fraud, forget their rights and obligations, and even for personal gain, knowledge and law, and leadership cheating, and thus pay, Promotion, incentives and other benefits, but also to a certain extent, the loss of authenticity of accounting information protection.

Therefore, in order to meet the needs of enterprise management, managers also require the production of real accounting information. This is sufficient to show that in practice, why some companies set up two sets of true and false accounts to meet the different needs of the business interests of the reasons. So that only through the perfect internal control and strict external supervision in order to better ensure high-quality accounting information (Wang et al. 2015).

\section{The Current Situation Internal Control and the Role Internal Control Playing on Accounting Information Quality}

\subsection{China's Enterprise Internal Control Present Situation}

\subsubsection{Imperfect Corporate Governance Structure}

(1) The formal general meeting of shareholders

The company's equity is extremely concentrated in top management, so that 
management personnel increase the scope and boundary of the company control, resulting in the strange phenomenon of insider control that should not appear in the companies. Small and medium-sized equity holders of the company do not have the capacity to undertake to defray cost of participation in the general meeting of shareholders. Usually, small and medium shareholders do not attend the general meeting of shareholders. So it seems that the company's general meeting of shareholders often tends to show a non-existing situation.

(2) Poor board independence

The company's internal control mechanism for the operators and managers is weak. Actually, the operators and managers control the company's economic lifeline, the various issues. The board of directors is not only dominated by the general manager, but also it is dominated by the big equity owners on top. Therefore, the board of directors cannot stand in a fair position and be on behalf of all equity holders. The members of the board of supervisors are often deficient in their knowledge and ability, lack of experience and can't effectively fulfill their duties of supervision for the board of directors.

\subsubsection{Unreasonable Organizational Structure and Ambiguous Allocation of Powers and Responsibilities}

Some listed companies in China are the stock companies restructured by the state-owned enterprises. The organizations' structure of these companies above mentioned follows the old pattern and is lack of scientific rationality, without prior consideration of the effectiveness of the organization. The specific performance as follows: on the one hand, the boundary of responsibility is not clear; on the other hand, the organizational structure is complex and inefficient. Besides, unreasonable organizational structure and ambiguous allocation of powers and responsibilities will lead to a large number of unclear corporate governance, the prevalence of bureaucracy, lack of necessary communication between enterprise functions, insensitive information communication, only pay attention to local interests, and mutual shirk responsibility (Skaife et al., 2013). Eventually, the management efficiency will decrease significantly.

\subsubsection{Imperfect Corporate Culture Construction}

Management performance of enterprises in China is based on some profit index as the main basis and is lack of comprehensive inspection of other related indicators. This mechanism formed a profit-oriented culture. Besides, the imperfect rewards and punishment mechanism has serious negative effect on the management authorities. Authorities excessively pursuit of profit, ignore improvement of enterprise internal process, optimization of the management and enterprise long-term development. Under the influence of profit orientation, there are adverse selection and moral hazard problems in enterprise management.

\subsubsection{The Poor Independence of the Audit Supervision Department}

The main work of the audit department is to supervise the business activities, efficiency and effect of the enterprise. The financial department as an important branch of the enterprise, the work should be the focus of the auditing depart- 
ment to supervise. The discretion of the quality of accounting information is closely related to the auditing department. However, the status of audit departments in many enterprises in China has not been given enough attention, belonging to the administrative department. The daily audit affairs are directly controlled by the administrative department managers, leading to the lack of independence of the audit departments. The department's audit work can't be carried out normally. The audit results are often unfair. In particular, considering the financial aspect, the quality of accounting information is often cannot be guaranteed.

\subsection{The Role Internal Control Playing on Accounting Information Quality}

\subsubsection{Effective Internal Control Can Help Improve the Integrity and Transparency of Accounting Information}

The objectives of internal control require the efficiency and effectiveness of business activities. Effective internal control system is a full range of control to all aspects of business and all individuals engaged in business management activities. Reasonable and feasible internal control system can ensure the efficient operation of the enterprise, and can reasonably control, coordinate and evaluate the functions of various functional departments and personnel within the enterprise so as to urge the various departments and personnel of the enterprise to fulfill their duties, clear objectives and ensure the enterprise's Production and business activities in an orderly and efficient manner, thereby enhance the integrity and transparency of the accounting information provided by companies.

\subsubsection{Effective Internal Control Can Guarantee the Authenticity and Correctness of Accounting Information}

The objective of internal control requires the reliability of economic information and financial reporting. Effective internal control can ensure the confirmation, measurement, recording and reporting of accounting information accurately reflect the actual production and business activities, and timely discover and correct all kinds of mistakes, so as to ensure the authenticity and correctness of accounting information and to enable the accounting information provided by enterprises to accurately and promptly reflect the financial situation of enterprises, operating results and cash flow (Sheng, 2014).

\subsubsection{Effective Internal Control Can Guarantee the Legitimacy and Validity of Accounting Information}

The objectives of internal control require compliance with applicable laws and regulations. Internal control system can ensure that the country's policy, financial laws and regulations carry out within the enterprise. Sound internal control can supervise and control effectively any department, any enterprise internal circulation link. Besides, effective internal control system can reflect and correct timely various problems what had happened, so as to ensure national policy and financial laws and regulations to be implied effectively, ensure the legitimacy of corporate financial activities and improve the legitimacy of accounting informa- 
tion disclosure and effectiveness.

\section{Recommendations Based on Internal Control to Enhance the Quality of Accounting Information}

At present, due to the immaturity of the system, there are still many problems in internal control in China. In addition, due to poor regulation and accounting distortion phenomenon emerging in endlessly lead to low quality of accounting information and cause serious damage to policymakers and external investors. The internal control of enterprises has a great effect on improving the quality of accounting information. High-level internal control has the function of guaranteeing the reliability and relevance of accounting information for accounting information. Therefore, how to improve the quality of accounting information through internal control? In this paper, I give some suggestions as follows:

\subsection{Optimize the Corporate Governance Structure}

\subsubsection{Perfect the Ownership Structure of Corporate}

The ownership structure is the process of the distribution of control rights among the investors. Decentralized ownership structure will lead to lower corporate governance efficiency. The main reason for the failure of corporate governance structure in China is the unreasonable ownership structure. The main means can be taken to improve the ownership structure of enterprises: reduce of state-owned shares, raise the ratio of outstanding shares, introduce multiple investors and nurture institutional investors to ensure equity concentration (Gao and Wang, 2005).

\subsubsection{Optimize the Board of Directors and Board of Supervisors}

Enterprises should strengthen the optimization of independent director system, assist in strengthening supervisory management for the board of directors of executive directors and major shareholders, prevent the occurrence of violations of discipline, and gradually improve the accounting information quality system. Enterprises should also develop a system of remuneration and performance evaluation of directors, and set up professional committee in the board of directors in order to prevent the board of directors is too centralized power for accounting fraud. In addition, for the board of supervisors, it is necessary to improve the professionalism and independence of the board of supervisors and improve the operation procedures of the board of supervisors.

\subsection{Build a Reasonable and Clearly Defined Organization}

Enterprises should change the traditional organizational structure and establish a business process as the center, customer-oriented, flat organic organization structure. The advantages of the above organizational structure are: promote the growth of grassroots managers, improve the democratization of decision-making, save management costs, easy to understand the situation at the grassroots level, speed up information transmission and reduce information distortion. In addition, enterprises should note in the authorization: on the one hand, before 
authorization, internal responsibilities are clearly defined and divided; on the other hand, in the authorization, the enterprise should authorize in accordance with the prescribed procedures, cannot skip steps authorization and authorized persons exercise their functions and powers within the prescribed scope.

\subsection{To Establish a Good Enterprise Culture Atmosphere}

The value of corporate culture has been recognized by people, it is the core of the enterprise. China's many well-known large enterprises, such as Haier, TCL, Lenovo, are following the "culture is the soul of enterprise development" concept, shaping a culture with self-characteristics, enduring in the fierce competition. Chinese enterprises should give full consideration to their own situation to speed up the pace of enterprise culture construction. On the one hand, to strengthen the education and guidance of enterprise employees' spirit, including the way of thinking, ideals and beliefs, professional ethics, values and so on. Enterprise should put respecting people, understanding people, caring for people, cultivating people, reasonable employment, improving the staff's overall quality as the main content of enterprise culture construction and form the cultural atmosphere that is good for talents to stand out and use creative talents. On the other hand, formulate humanized rules and regulations. The more the systems of the enterprise are in line with human nature, the more able to inspire the work enthusiasm of the staff, the more they can promote the formation and dissemination of corporate culture. In addition, if employees are "bathing" in the enterprise culture atmosphere full of cohesion and centripetal force, their goals and beliefs will be more convergence and the implementation of internal control will be more effective. As a result, the quality of accounting information will naturally be guaranteed.

\subsection{To Establish Effective Internal and External Supervision System}

Internal audit can not only help enterprises to improve operational efficiency and supervise internal control system, but also help enterprises to reduce accounting information distortion and improve the quality of accounting information. On the one hand, enterprises should improve the independence of internal audit. Internal auditors shall independently conduct auditing accounting activities, supervise economic activities and evaluate internal control systems, and report directly to the board of directors or the audit committee (Masli et al., 2010). On the other hand, enterprises should identify and adjust position of the internal audit activity. Enterprises should carry on the audit knowledge training to the enterprise management personnel and make them aware of the importance of internal audit to the enterprise. In addition, enterprises should strictly select, hire and train internal auditors, and provide adequate property for internal audit institutions so that the audit can be carried out properly.

The external supervision departments should actively coordinate and rationalize the division of labor, clarify the scope of each other's functions and streng- 
then the exchange of information, so as to change the decentralized supervision into joint supervision and form an effective supervision force to carry out comprehensive monitoring of the internal control of enterprises. Enterprises should vigorously develop the CPA self-regulatory organizations and control mechanisms to strengthen the Council and its industry supervision, so that it can consciously resist the industry malpractice, truthfully issued an internal control report. In addition, enterprises can use the news media, public opinion and other social supervision of the force to restrain the lawless elements to improve the efficiency of supervision, thereby ensuring that financial reporting and disclosure of information is accurate and reliable (Gao and Wang, 2005).

\section{Conclusion}

With the development of economic globalization and the increasingly fierce market competition, accelerating the development of enterprises is a long and arduous task. In order to meet the needs of the development of socialist market economy, the real and reliable accounting information is very important. Highquality accounting information plays an important role in the internal corporate governance structure, which enables the board of directors to make a correct judgment on the company's operating performance. High-quality accounting information reduces the degree of information asymmetry, enhances the liquidity of the capital market, thus reducing the company's cost of equity and contributing to the improvement of the company's performance. High-quality accounting information directly determines the effectiveness of the capital market and the allocation of social resources efficiency.

At present, China's accounting information distortion is still quite serious, for many reasons; however, imperfect internal control and the poor implementation of internal control are the main reasons. Internal control is the control of the source accounting information. Effective internal control can eliminate the incentive to distortion of accounting information, a fundamental guarantee of accounting information quality. Therefore, enterprises need to start from the internal control, to seek the best solution. Through the continuous sound improving the internal control system, enterprises ensure the accounting information to be true and reliable.

\section{References}

Altamuro, J., \& Beatty, A. (2010). How Does Internal Control Regulation Affect Financial Reporting. Journal of Accounting and Economics, 49, 58-74. https://doi.org/10.1016/j.jacceco.2009.07.002

Chen, J., Chan, K. C., Dong, W., \& Zhang, F. (2015). Internal Control and Stock Price Crash Risk: Evidence from China. European Accounting Review, 10, 1-45.

Gao, Y. B., \& Wang, H. (2005). Some Thoughts on Accelerating the Construction of Internal Accounting Control. Accounting Research, 2, 3-10.

Masli, A., Peters, G. F., Richardson, V. F., \& Sanchez, J. M. (2010). Examining the Potential Benefits of Internal Control Monitoring Technology. Accounting Review, 85, 10011034. 
https://doi.org/10.2308/accr.2010.85.3.1001

Sheng, J. (2014). The Impact of Internal Control on Accounting Information Quality. Jilin: Jilin University.

Skaife, H. A., Veenmanb, D., \& Wangerin, D. (2013). Internal Control over Financial Reporting and Managerial Rent Extraction: Evidence from the Profitability of Insider Trading. Journal of Accounting and Economics, 55, 91-110.

https://doi.org/10.1016/j.jacceco.2012.07.005

Wang, J., Bloomberg, Xiong, Y. R., Zhang, P., \& Zhang, J. (2015). The Effectiveness of Internal Control and the Quality of Accounting Information-The Introduction of Western Internal Control Research Literature and the Prospect in the Background of China's System (I). Accounting Review, 6, 87-95.

Zhang, X. X. (2014). Analysis on the Influence of the Current Situation of Enterprise Internal Control on Accounting Information Quality. Financial Marketing, 21, 123-124.

Submit or recommend next manuscript to SCIRP and we will provide best service for you:

Accepting pre-submission inquiries through Email, Facebook, LinkedIn, Twitter, etc. A wide selection of journals (inclusive of 9 subjects, more than 200 journals)

Providing 24-hour high-quality service

User-friendly online submission system

Fair and swift peer-review system

Efficient typesetting and proofreading procedure

Display of the result of downloads and visits, as well as the number of cited articles

Maximum dissemination of your research work

Submit your manuscript at: http://papersubmission.scirp.org/

Or contact jfrm@scirp.org 